\title{
Effect of the Organic Layer Thickness on the Device Performance of Organic/Inorganic Solar Cells Having 30\% Cobalt's Chloride Doped POT
}

\author{
R. K. Fakher Alfahed ${ }^{*}$, K. I. Ajeel ${ }^{2}$ \\ ${ }^{1}$ Al-Nahrain Nano renewable Energy Research Center; AL-Nahrain University, Iraq. \\ 2 Physics department; College of Education for pure sciences; University of Basrah, Iraq. \\ * Corresponding author. Tel.: 009647804373779; email: rrr80kkk@yahoo.com. \\ Manuscript submitted October 24, 2016; accepted March 10, 2017. \\ doi: 10.17706/ijmse.2017.5.1.28-34
}

\begin{abstract}
The Photovoltaic device is fabricated by depositing the prepared polymer on the n-type silicon by spin coating method. The influence of thickness is noted in which the decrease in thickness led to an increase in efficiency of $30 \%$ cobalt's chloride doped POT. The better efficiency of the prepared devices is increased by decreasing the thickness to be $3.224 \%$ at the thickness $39.75 \mathrm{~nm}$ for (Au/POT-30\% cobalt's chloride/n-type Si/Al ) with the open voltage circuit ( $0.48 \mathrm{~V}$ ), short circuit current $\left(21.257 \mathrm{~mA} / \mathrm{cm}^{2}\right)$ and full factor ( 0.316$)$ which are tested under illumination with intensity of $100 \mathrm{~mW} / \mathrm{cm}^{2}$.
\end{abstract}

Keywords: Poly (O-Toluidine), cobalt's chloride, solar cells.

\section{Introduction}

The supplied energy by solar cells is considered as a renewable energy sources and its promising energy in the future [1] however, the thin film photovoltaic technology provide a reduced cost in addition to having an interesting optical and electronic properties such as silicon solar cells which have power conversion efficiency around 24\% [2], [3]. The organic solar cells have been taken attention of the researcher due to its properties such as optical and electrical characteristics, inexpensiveness, environmental stability and low cost [4]. Thus, the many attempts have been made to look for high-efficiency, low-cost solar cells. A promising approach is the use of organic semiconductors such as the polymers. Organic photovoltaic devices consist of a multi-layer structure to fabricate it like bulk heterojunction [5]-[8] and heterojunction methods [9], [10]. To significantly enhance the photovoltaic efficiency still one of the most important tasks for the polymer photovoltaic cells. The conversion process of light to electricity includes four steps: (a) light absorption and exciton formation, (b) exciton dissociation, (c) charge transport and (d) charge collection. Absorption of incident light by active layer is equivalent to electron-hole pair (exciton) creation. The absorption process makes the molecules of material to be in excited state. As a matter of fact, the organic materials absorbs small amount of the incident light that related to energy gaps of semiconductor organic materials whereas the mostly of these materials have energy gaps not less than $2(\mathrm{eV})$ which gave a probability to absorb about $30 \%$ of incident light. In addition to other factors like crystallization of the films, temperature of annealing films leading to morphology factor of the film surface and reflection losses which also related to surface of active layer [11], [12]. The generated excitons as result of incident light will be diffused to the donor: acceptor interface (junction) before decay as radiation. The excitons stationed at the 
donor/acceptor interface will be separated into dissociated charge carriers that mean the electron (hole) at the interface transfer to adjacent acceptor (donor) molecule. This step of carriers transfer is usually exothermic and very fast ( 100fs) [13], [14]. Dissociated charge carriers will be collected by metals electrodes. The absorption is majority determined by properties of conjugated polymer materials. Exciton diffusion length in general conjugated polymer materials is around 5-20nm [15]. Efficiency of charge carriers transfers are depended on morphology of the active layer, and charge carriers collection is decided by: (a) the charge carrier mobility in corresponding materials and (b) active layer/electrode interface. These steps are affected by the chemical structure of active materials, that is, the donor and acceptor, and the morphology of the active polymer film [15]-[20]. The heterojunction method (organic / inorganic junction) is effective way in presenting work, whereas, the prepared polymer of POT, cobalt's chloridedoped POT deposits on the n-type silicon and, then, the J-V characteristics are investigated in dark and illumination.

\section{Procedure and Experimental Work}

\subsection{Preparation of Poly (o-Toluidine) (POT)}

$10 \mathrm{mg}$ of the obtained polymer (POT) by chemical polymerization process (which is characterized by FT-IR, XRD, and SEM) are dissolved in $1 \mathrm{ml}$ of formic acid ( $\mathrm{HCOOH}$ provided by sigma Aldrich) while the cobalt's chloride $\left(\mathrm{CoCl}_{2} \cdot 6 \mathrm{H}_{2} \mathrm{O}\right)$ (provided by sigma Aldrich) is dissolved in formic acid also to be in concentration of $0.042 \mathrm{M}$. The doping process is don as $30 \%$ volume ratio of the dissolved cobalt's chloride with respect to dissolved polymer is mixed with dissolved POT by using magnetic stirrer for $5 \mathrm{~h}$ [21], [22].

\subsection{Abrication of Solar Cells}

The photovoltaic devices including single layer of polymers are fabricated as following steps:

First step: preparation of silicon wafer samples (having resistivity of $1-20 \Omega,<100>$ oriented and thickness of $300 \pm 30 \mu \mathrm{m}$ ) which are used as substrates to deposit polymer materials on it, that done by etching process with Hydrofluoric acid (HF) to remove silicon dioxide layer and other undesired material from the surface of wafer. The etching process is done under room temperature by diluted Hydrofluoric acid (diluted by $\mathrm{H}_{2} \mathrm{O}$ to have concentration of $30 \% \mathrm{HF}$ ) for three times and every etching time was 5 minutes, then etched samples are washed by distilled water and finally carried out to keep them in methanol to be sure non-growth oxide layer once.

Second step: thin films preparations of polymers are prepared by using spin coating method to deposit it on the etched silicon substrate. The different thickness layers of $30 \%$ Cobalt's chloride-doped POT are prepared in which the polymer is synthesis according to our previous study [23]. The thicknesses of prepared thin films by spin coating method are measured by ellipsometry equipment.

Third step: after deposit a polymers the aluminum electrode (has work function ranging between 3.7 to $4 \mathrm{eV}$ ) [24] is deposited as back electrode by using EDWARD Auto 306 vacuum coater under low pressure condition which is approximately $10^{-5}$ torr (inside vacuum chamber) to reduce oxidation factor and thickness of (100 nm)while the gold electrode (has work function 5.1eV) [24] is deposited after deposit the polymer by using Q150R Rotary-Pumped Sputter Coater as top electrode with thickness not more than 20 $\mathrm{nm}$ to be high transparent for incident light and the area of gold electrode is $0.03 \mathrm{~cm}^{2}$. Architecture of the prepared solar cell looks like as in Fig.1. 


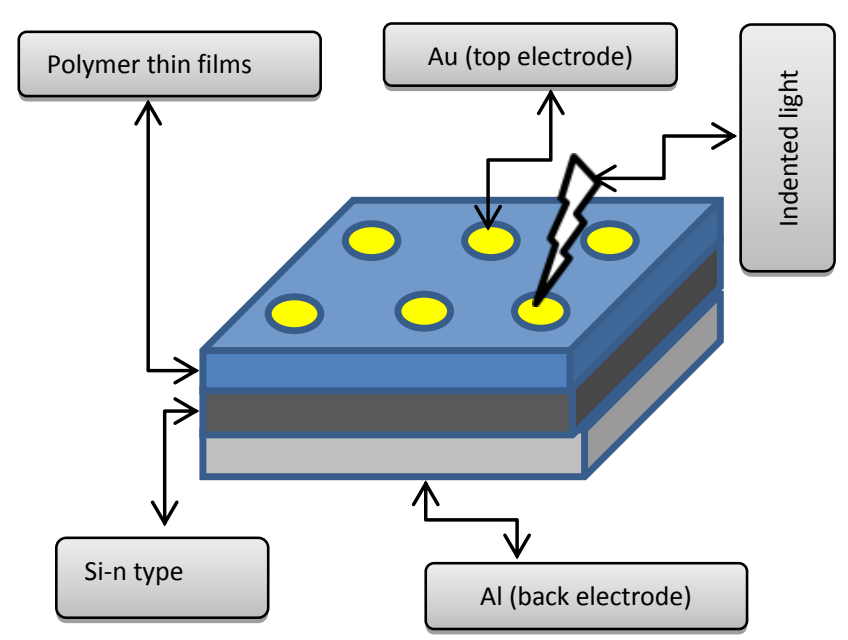

Fig. 1. Solar cell structure.

\section{Results and Discussion}

The effect of different thicknesses of the 30\% cobalt's chloride doped POT layer on the performance of solar cell $(\mathrm{AL} / \mathrm{Si} / 30 \%$ doped $\mathrm{POT} / \mathrm{Au}$ ) is studied according to J-V characterizations which are measured by using Keithley electrometer instruments (Model 65174) in dark, under illumination with intensity of $100 \mathrm{~mW} / \mathrm{cm}^{2}$ and room temperature (R.T.) as showed in Fig. 2. Thicknesses of the prepared layers are measured by ellipsometry equipment to be $(39.75,46.72,56.69,68.9) \mathrm{nm}$. The performance of prepared devices for different volume ratios are studied according to these parameters as tabulated in table 1 in which the short circuit current (Jsc) and open circuit voltage (Voc) are measured directly from the figures while the series resistance (Rs), shunt resistance (Rsh), fill factor (FF) and power conversion efficiency are calculated according to equations $(1,2,3,4)$, respectively [25]-[28].

Table 1. Parameters Calculated from (J-V) Characteristic of POT-30\% Cobalt'S Chloride with Different

\begin{tabular}{c|ccccccccc}
\multicolumn{10}{c}{ Thicknesses } \\
\hline $\begin{array}{c}\text { POT- 30\% } \\
\begin{array}{c}\text { Cobalt's } \\
\text { chloride }\end{array}\end{array}$ & $\begin{array}{c}V o c \\
(V)\end{array}$ & $\begin{array}{c}J_{s c} \\
\left(\mathrm{~mA} / \mathrm{cm}^{2}\right)\end{array}$ & $\begin{array}{c}V p \\
(V)\end{array}$ & $\begin{array}{c}J_{p} \\
\left(\mathrm{~mA} / \mathrm{cm}^{2}\right)\end{array}$ & $\begin{array}{c}P \max \\
\left(\mathrm{mW} / \mathrm{cm}^{2}\right)\end{array}$ & $\begin{array}{c}F F \\
(a . u .)\end{array}$ & $\begin{array}{c}\eta \\
(\%)\end{array}$ & $\begin{array}{c}R s \\
(\Omega)\end{array}$ & $\begin{array}{c}R s h \\
(\Omega)\end{array}$ \\
\hline $68.9 \mathrm{~nm}$ & 0.4 & 15.05 & 0.27 & 10.66 & 2879.55 & 0.478 & 2.879 & 174.3 & 6599.4 \\
$56.69 \mathrm{~nm}$ & 0.43 & 24.2 & 0.23 & 13.13 & 3019.29 & 0.29 & 3.019 & 325 & 1512.9 \\
$46.72 \mathrm{~nm}$ & 0.48 & 22.99 & 0.24 & 13.07 & 3137.36 & 0.2842 & 3.137 & 411.06 & 1772.4 \\
$39.75 \mathrm{~nm}$ & 0.48 & 21.26 & 0.24 & 13.43 & 3223.92 & 0.316 & 3.223 & 461.29 & 2398 \\
\hline
\end{tabular}

$$
\begin{gathered}
R_{s}=(I / V)^{-1} \\
R_{s h}=(I / V)^{-1} \\
F F=\left(V_{\max } \cdot J_{\max }\right) /\left(V_{o c} \cdot J_{s c}\right)=P_{\max } /\left(V_{o c} \cdot J_{s c}\right) \\
\eta=\left(P_{\max } / P_{i n}\right)=\left(V_{\max } \cdot J_{\max }\right) / P_{\text {in }}=\left(F F \cdot V_{o c} \cdot J_{s c}\right) / P_{\text {in }}
\end{gathered}
$$




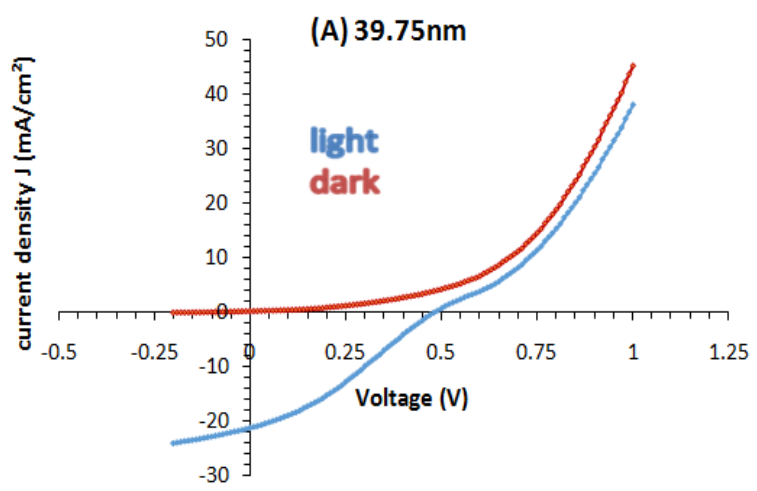

Fig. 2(A). J-V curves of POT- 30\% cobalt chloride solar cell device measured with thickness of 39.75 nm.

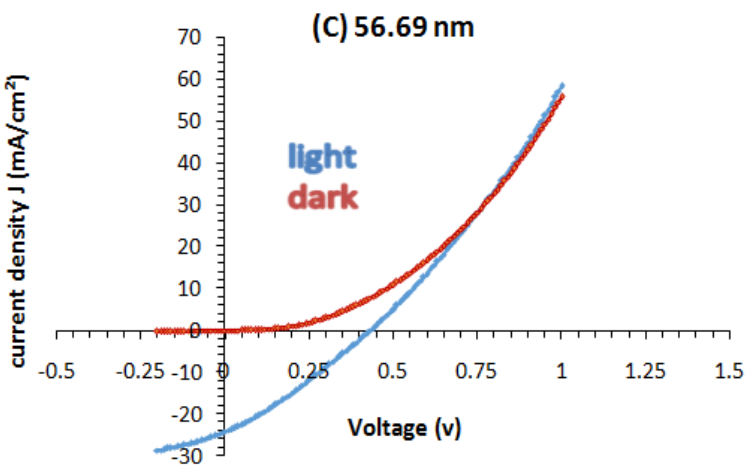

Fig. 2(C). J-V curves of POT- 30\% cobalt chloride solar cell device measured with thickness of 56.69 nm.

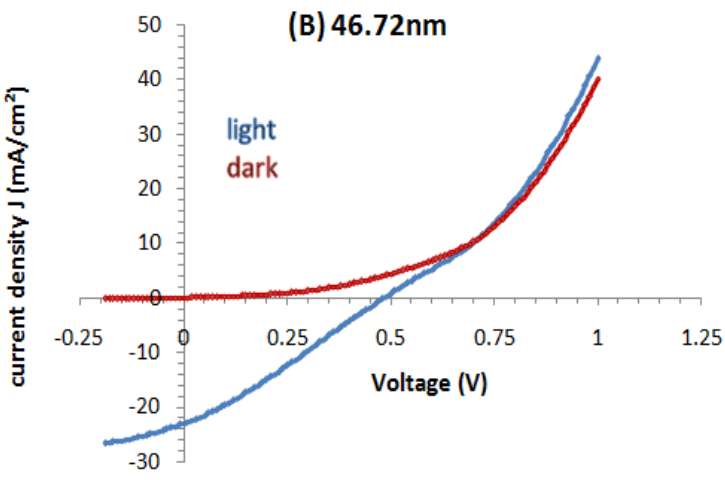

Fig. 2(B). J-V curves of POT- 30\% cobalt chloride solar cell device measured with thickness of 46.72 nm.

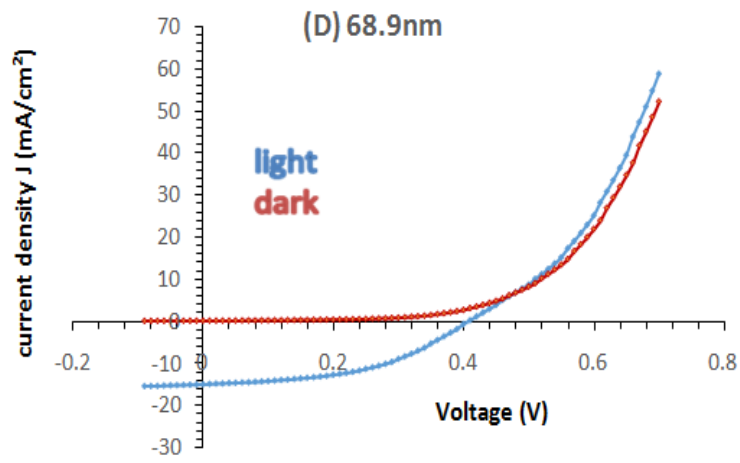

Fig. 2(D). J-V curves of POT- 30\% cobalt chloride solar cell device measured with thickness of 68.9 nm.

The J-V curves showed that, the short circuit currents $\left.U_{s c}\right)$ are $(15.0513,24.2017,22.999,21.257)$ $\mathrm{mA} / \mathrm{cm}^{2}$ at the thickness of $(68.9,56.69,46.72,39.75) \mathrm{nm}$ respectively. This result indicated to, the better current density which is recorded at thickness (56.69) $\mathrm{nm}$ due to morphology of absorption layer in addition to shunt resistance $\left(R_{s h}\right)$ influence is low that leads to an increase in the current density and compared with other thicknesses and also the high series resistance $\left(R_{s}\right)$ leads to reduce current density [29]. The fill factor $(F F)$ is calculated by using equation (5.9) to recording the best one which is (0.487) at the thickness $(68.9 \mathrm{~nm})$ in comparison with other thicknesses in which decreasing a FF related to parameters that were used to calculate it, series resistance $\left(R_{s}\right)$ and shunt resistance $\left(R_{s h}\right)$. The $\left(R_{s}\right)$ are dependent on a voltage through physical mechanisms aroused at interfaces within the photovoltaic device. Transparent contact layers as gold $(\mathrm{Au})$ and carrier transporting interlayers of various types increase significantly series resistance. Interfaces between the active layer (30\%doped POT) and interlayers may added more series resistance because of partial energy level alignment affected on optimal interface charge transfer. Furthermore, the influence of the charge carrier transport within the active layers of device leads to an increase in the series resistance [30], [31] while open voltage circuit $\left(V_{o c}\right)$ increased when the thickness decreased due to a decrease in the recombination or charge trapping whereas the charge carrier recombination barrier formed by cascade structure [32]. Finally the power conversion efficiency of prepared devices with different thicknesses is increased by decreasing thickness of polymer layer (see Fig. 3) because of parameters in addition the morphology of absorption layer. 


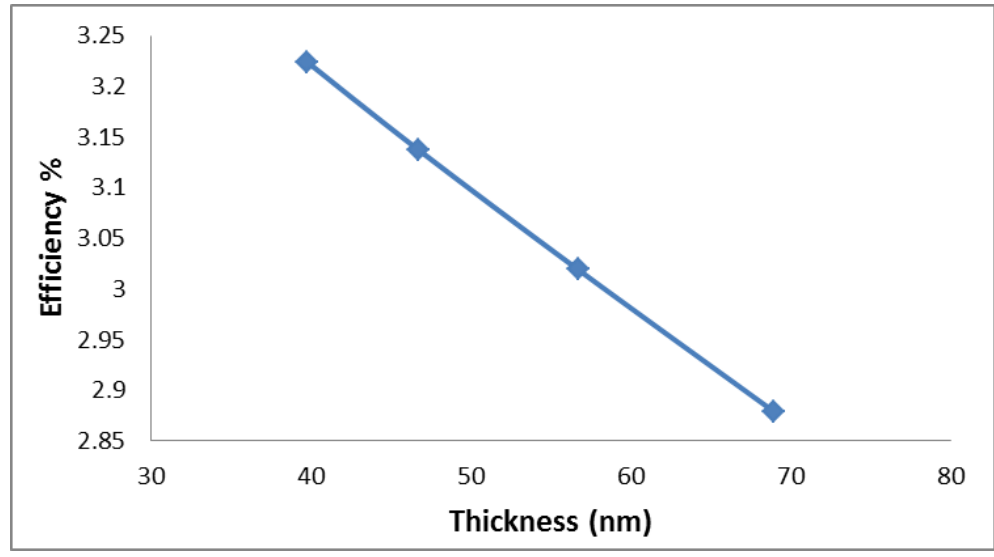

Fig. 3. Relation between efficiency and thickness.

Thin film (39.75 $\mathrm{nm}$ ) shows that high charge carriers and excision nobilities which reflects better power conversion efficiency which is (3.224\%), while the other efficiencies are decreased with increasing the thickness as result as flat and texture type of high-reflective thin films (back layer working as the solar cell back electrode). The texture dependent on: (a) the film thickness; (b) fabrication condition which meant that, when the film become thin the surface texture is suitable to light trapping [33]-[37].

\section{Conclusion}

The chemical polymerization of poly (O-Toluidine) was successful prepared and agreed with previous studied. The doping process of prepared polymer by cobalt's chloride reflected a good behavior in photovoltaic devices. The solar cell is fabricated using spin coating method. The deposited polymers on silicon substrate have structure (Au/polymer/n-silicon/Al) where the gold ( $\mathrm{Au}$ ) and aluminum (Al) are used as top and back electrodes respectively. The power conversion efficiency of solar cell $\mathrm{Au} / 30 \%$ cobalt's chloride doped POT/ Al) is tested for different thickness and then the better efficiency is recorded at thickness $39 \mathrm{~nm}$ to be $(3.22 \%)$. The efficiencies of prepared solar cells devices are decreased with increasing the thickness as result as flat and texture type of high-reflective thin films.

\section{Acknowledgements}

The authors would like to thank Education College for Pure Sciences/ University of Basrah, and thanks extend to Ministry of Higher Education and Scientific Research (Iraq). I would like to express my sincere gratitude to Sheffield Hallam University/Material and Engineering Research Institute/UK for supported us and provide all the capabilities to complete the research in their laboratories.

\section{Reference}

[1] Guo, Y. L., Liu, C., Inoue, K., Harano, K., Tanaka, H., \& Nakamura E. (2014). Enhancement in the efficiency of an organic-inorganic hybrid solar cell with a doped P3HT hole-transporting layer on a void-free perovskite active layer. J. Mater. Chem. A, 2(34), 13827-13830.

[2] Rim, S. B. (2010). Optimization of Organic Solar Cells. Ph.D thesis, Department of Electrical Engineering and THE Committee on Graduate Studies of Stanford University.

[3] He, Y. J., You, J. B., Dou, L. T., Chen, C. C., Richard, E., Cha, K. C., et al. (2012). High performance low band gap polymer solar cells with a non-conventional acceptor. Chem. Commun., 48(61), 7616-7618.

[4] Choi, J., Panthi, G., Liu, Y. N., Kim, J. W., Chae, S. H., Lee, C., et al. (2015). Keratin/poly (vinyl alcohol) blended nanofibers with high optical transmittance. Polymer, 58, 146-152.

[5] Zhao, C., Qiao, X. F., Chen, B. B., \& Hu, B. (2013). Thermal annealing effect on internal electrical 
polarization in organic solar cells. Organic Electronics, 14(9), 2192-2197.

[6] Strange, M., Plackett, D., Kaasgaard, M., \& Krebs, F. C. (2008). Biodegradable polymer solar cells. Solar Energy Materials \& Solar Cells, 92(7), 805-813.

[7] Sun, S. S., \& Sariciftci, N. S. (2005). Organic Photovoltaic: Mechanisms, Materials and Devices. Boca Raton : CRC Press.

[8] Blom, P. W. M., Vissenberg, M. (2000). Charge transport in poly (p-phenylene vinylene) light-emitting diodes. Materials Science and Engineering: R: Reports, 27(3), 53-94.

[9] Ziadan, K. M., Hussein, H. F., Hassan, A. K., \& Ajeel, K. I. (2013). Study of the electrical characteristics of poly(o-toluidine) doped with para-Toluene sulphonic acid/N-type silicon heterojunction solar cells, Proceedings of the Solar Asia conference-2013. Kuala Lumpur, Malaysia: CIUM.

[10] Ziadan, K. M., Hussein, H. F., \& Ajeel, K. I. (2012). Study of the electrical characteristics of poly(o-toluidine) and application in solar cell. Energy Procedia, 18, 157-164.

[11] Zerza, G., Brabec, C. J., Cerullo, G., Silvestri, D. S., \& Sariciftci, N. S. (2001). Ultrafast charge transfer in conjugated polymer-fullerene composites. Synthetic Metals, 119(1-3), 637-638.

[12] Brabec, C. J., Zerza, G., Cerullo, G., Silvestri, D. S., Luzzati, S., Hummelen, J. C. (2001). Tracing photoinduced electron transfer process in conjugated polymer/fullerene bulk heterojunctions in real time. Chemical Physics Letters, 340(3), 232-236.

[13] Blom, P. W. M., Mihailetchi, V. D., Koster, L. J. A., \& Markov, D. E. (2007). Device physics of polymer:fullerene bulk heterojunction solar cells. Adv. Mater., 19(12), 1551-1566.

[14] Peumans, P., Yakimov, A., \& Forrest, S. R. (2003). Small molecular weight organic thin-film photodetectors and solar cells. J. Appl. Phys., 93(7), 3693-3723.

[15] Chen, L. M., Hong, Z., Li, G., \& Yang, Y. (2009). Recent progress in polymer solar cells: manipulation of polymer: fullerene morphology and the formation of efficient inverted polymer solar cells. Advanced Materials, 21(14-15), 1434-1449.

[16] Facchetti, A. (2007). Semiconductors for organic transistors. Mater. Today, 10(3), 28-37.

[17] Kraft, A., Grimsdale, A. C., \& Holmes, A. B. (1998). Electroluminescent conjugated polymersĐseeing polymers in a new light. Angew. Chem. Int. End Engl., 37, 402-428.

[18] Gratzel, M. (2001). Photo electrochemical cells. Nature, 414(6861), 338-344.

[19] Silva, C. (2013). Organic photovoltaics:Some like it hot. Nat. Mater., 12(1), 5-6.

[20] Alfahed, R. K. F., \& Ajeel, K. I. (2015). Effect of cobalt's chloride on the electrical properties of poly (O-toluidine). International Journal of Materials Science and Engineering, 3(4), 319-326.

[21] Alfahed, R. K. F., \& Ajeel, K. I. (2015). Electrical properties of blend polymers of polyvinyl alcohol/ poly(otoluidine). IJSBAR, 23, 173-182.

[22] Deibel, C., Strobel, T., \& Dyakonov, V. (2010). Role of the charge transfer state in organic donor-acceptor solar cells. Adv. Mater., 22(37), 4097-4111.

[23] Alfahed, R. K. F., Ajeel, K. I., \& Hassan, A. K. (2016). Effect of cobalt's chloride on the optical properties of poly (O-toluidine) and study of it's organic/inorganic solar cell. European Scientific Journal, 12(3), 224-234.

[24] Riedel, I., Martin, N., Giacalone, F., Segura, J. L., Chirvase, D., Parisi, J., et al. (2004). Polymer solar cells with novel fullerene based acceptor. Thin Solid Films, 451, 43-47.

[25] Dennler, G., Lungenschmied, C., Neugebauer, H., Sariciftci, N. S., \& Labouret, A. (2005). Flexible, conjugated polymer-fullerene-based bulk-heterojunction solar cells: Basics, encapsulation, and integration. J. Mater Res., 20(12), 3224-3233.

[26] Kietzke, T. (2008). Recent advances in organic solar cells. Advances in Optoelectronics, 2007, 15. 
[27] Teng, X. (2012). Modifying the Organic/Electrode Interface in Organic Solar Cells (OSCs) and Improving the Efficiency of Solution-Processed Phosphorescent Organic Light-Emitting Diodes (OLEDs). Ph.D. thesis, Iowa State University.

[28] Skjolding, L., Spegel, C., Ribayrol, A., Emneus, J., \& Monteius, L. (2008). Characterization of nano-interdigitated electrodes. Journal of physics, 100(5), 052045.

[29] Cowan, S. R., Banerji, N., Leong, W. L., \& Heeger, A. J. (2012). Charge formation, recombination, and sweep-out dynamics in organic solar cells. Adv. Funct. Mater., 22(6), 1116-1128.

[30] Wang, L. D., Zhao, Y. X., Wang, G. H., Zhou, H., Geng, C., Wu, C. Q., et al. (2014). Enhancing the efficiency of $\mathrm{ZnO} / \mathrm{Cu}_{2} \mathrm{O}$ inorganic nanostructure solar cells simply by $\mathrm{CdS}$ quantum dots. Solar Energy Materials \& Solar Cells, 130, 387-392.

[31] Skjolding, L., Spegel, C., Ribayrol, A., Emneus, J., \& Monteius, L. (2008). Characterization of nano-interdigitated electrodes. Journal of Physics, 100(5), 052045.

[32] Abdullah, A. Q., Ghafor, W. A., \& Allaibi, S. (1999). DC conduction mechanism and relaxation processes in poly(vinylalcohol graft Rhodamine B). Iraqi J. Polymer, 3(1), 93-104.

[33] Electrical and electronics properties slate of the art-componcluding encyclopedia repnnl. John Wiley \& Suns New.

[34] Yakuphanoglu, F., Erol, I., Aydogdu, Y., \& Ahmedzade, M. (2002). Electrical and optical properties of (poly 2-(3-1,2-,3,4-tetrahydronaphtyl-1-3-methylcyclobutyl)-2-hydroxyethylmethacrylate, Materials letters, 57(1), 229-236.

[35] Hussein, H. F., Ghafor, W. A., \& Hadad, A. M. (2000). Electric properties of carbon black filled benzidine terminated poly(p-amino benzaldehyde) films. Iraqi J. Polymer, 4, 59-68.

[36] Riedel, I., Martin, N., Giacalone, F., Segura, J. L., Chirvase, D., Parisi, J. (2004). Polymer solar cells with novel fullerene based acceptor. Thin Solid Films, 451, 43-47.

[37] Yamamoto, K., Yoshimi, M., Suzuki, T., Tawada, Y., Okamoto, Y., \& Nakajima, A. (1998). Below 5 mm thin film poly-Si solar cells on glass substrate fabricated at low temperature. Proceedings of the 2nd World Conference on Photovoltaic Energy Conversion (p. 1284). Vienna.

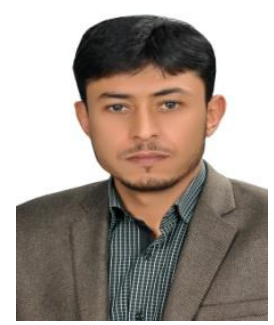

Raed Kadhum Fakher Alfahed is a Ph.D at Al-Nahrain Nano renewable Energy Research Center; AL-Nahrain University, Iraq. He was born in Thi-Qar, Iraq in 1981. He has a master degree in electronic instrumentation from the Osmania University, Physics department in 2011. After that he worked in Thi-Qar University as lecturer for one year. Next, the author studies the Ph.D in Basrah University, physics department in specialization of thin films. 